\title{
Supplementary Information: Stabilization of Bilgewater Emulsions by Shipboard Oils
}

Jared Church $^{\mathrm{a}}$, Grant C. Daniels ${ }^{\mathrm{b}}$, Jeffrey G. Lundin ${ }^{\mathrm{b}}$, Woo Hyoung Lee ${ }^{\mathrm{c}}$, Danielle Paynter ${ }^{\mathrm{a}}$
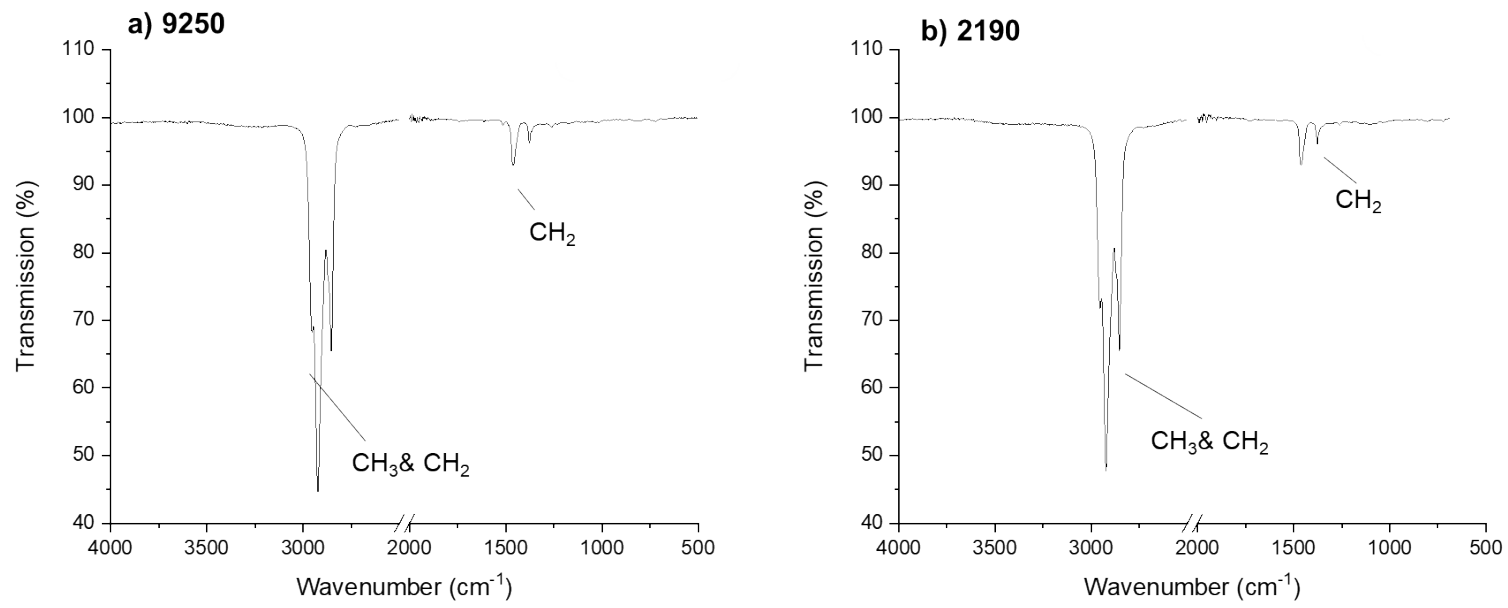

Figure S1. Infrared transmission of extracts from water exposed to a) 9250 and b) 2190 prominent functional groups

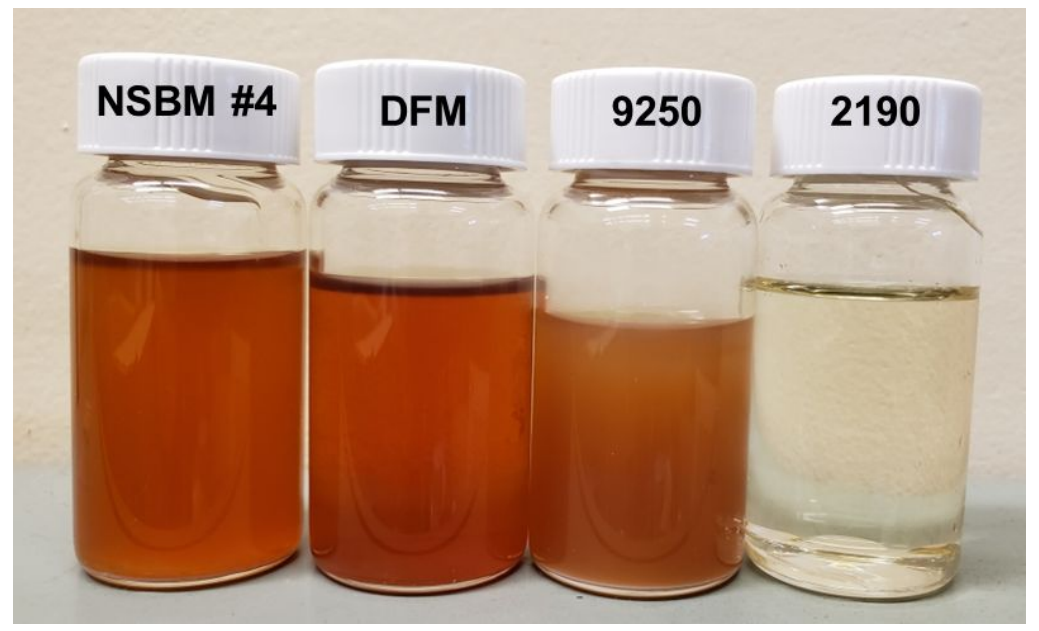

Figure S2. Oil samples after exposure to DI water for $24 \mathrm{hrs}$ 